IP Periodica Polytechnica Civil Engineering

\author{
59(4), pp. 475,486 2015 \\ DOI: $10.3311 /$ PPci.7364 \\ Creative Commons Attribution (1) \\ RESEARCH ARTICLE
}

\section{Effects of Warm Mix Asphalt Additives on Aging Characteristics of Bituminous Mixtures}

Peyman Aghazadeh Dokandari, Ali Topal

Received 19-02-2014, revised 05-08-2014, accepted 25-01-2015

\begin{abstract}
In recent decades, the utilization of the warm mix technologies in pavement constructions is increasing rapidly with rise in public environmental awareness. The durability of a pavement highly depend on the behavior of the pavement against aging induced failures. Therefore this study encompasses the evaluation of short- and long-term aging characteristics of four kinds of Warm Mix Asphalt (WMA) additives. Additives distinctly assessed in this study, consist of two non-foaming (organic and chemical) and two foaming(synthetic and natural zeolite) additives. In order to appraise the proportion of hardening of mixtures containing different kinds of additives, indirect tensile strength (ITS) values of both short- and long-term aged specimens were determined. Based on relative aging indices derived from the ratio of ITS values of aged and unaged specimens, comparisons were made between the additives assessing the impact of their utilization on aging characteristics of WMA.
\end{abstract}

\section{Keywords}

Warm mix asphalt $\cdot$ Durability $\cdot$ Natural zeolite $\cdot$ Synthetic zeolite Organic additive $\cdot$ Chemical additive

\section{Peyman Aghazadeh Dokandari}

Graduate School of Natural and Applied Sciences, Dokuz Eylul University, 35160, Buca, Izmir, Turkey

e-mail: ali.topal@deu.edu.tr

\section{Ali Topal}

Department of Civil Engineering, Faculty of Engineering, Dokuz Eylul University, 35160, Buca, Izmir, Turkey

\section{Introduction}

Most of the field pavement practices around the world consist of the conventional Hot Mix Asphalt (HMA). In recent decades, implementing of Warm Mix Asphalt (WMA) technologies has gained popularity in Europe and some other countries such as in Australia and the United States of America. The goal of WMA technologies is to obtain required strength and durability which is equivalent to or even better than HMA pavements.

Since the early $20^{\text {th }}$ century the global warming has become one of the important issues of the world as a result of human activities such as burning fossil fuels [1]. It is noticeable that a considerable amount of fossil fuels is burned in the production and application of HMA pavements. Beside the abundant cost of energy consumptions, this also causes the release of plentiful amounts of greenhouse gases which participate in global warming phenomenon and have an adverse effects on climate change [2,3]. The rise in public environmental awareness and economical considerations, have brought innovating ideas on burning less fossil fuels in order to stop global warming and constructing more sustainable pavements. One of these ideas is to simply reduce the viscosity of the base bitumen in order to make mixing and compaction processes being carried out at lower temperatures. In this context, a number of new processes and products was developed and various WMA additives were introduced to the market. Generally the technologies which their functioning principle is based on this idea are called WMA technologies. Typically, the mixing temperatures in the WMA technologies range from 100 to $140^{\circ} \mathrm{C}\left(212-280^{\circ} \mathrm{F}\right)$ while the mixing temperatures in conventional HMA technology is between 150 and $180^{\circ} \mathrm{C}\left(300-350^{\circ} \mathrm{F}\right)[4$ ]. Commonly WMA additives on the market consist of non-foaming and foaming additives based on their working principles [4]. Non-foaming additives simply reduce the viscosity of the base bitumen by making changes on internal properties of the base bitumen since the foaming additives such as synthetic and natural zeolites implement a different technique to make the mixing and compaction achievable in lower temperature. This technique is to basically increase the volume of the base bitumen by steaming effects. Increase in volume of the bitumen facilitates the coatability of the aggregates with bi- 
tumen. Release of tiny steam bubbles over the boiling point of water $\left(100^{\circ} \mathrm{C}\right)$ for a period of several hours can protract laying time with an improved workability. This study targets to evaluate the effects of two kinds of non-foaming additives (organic and chemical) and two kinds of foaming (synthetic and natural zeolites) on aging characteristics of bituminous mixtures.

Premature failures of asphalt pavements are often caused by diminishing of the binding forces in the mixture by the effect of moisture or mechanical stresses or aging of bitumen. The durability of asphalt pavement is a measure of its level of resistance to hardening (also called aging) over time [5]. The effect of time and environmental factors on the aging of bitumen has been a subject of continuous interest [6]. Earlier studies conducted on the effect of temperature and relative humidity on the oxidation of bitumen as a function of exposure time showed that the rate of oxidation is dependent on both of these environmental factors [6. 7]. The effect of ambient temperature on the characteristics of the bitumen is rather well documented. Petersen [8] pointed out that three basic factors control the changes that would result in aging in bitumen. Fist factor better called volatilization is the loss of the oily components of bitumen by volatility or by absorption of porous aggregates. Second factor called oxidation is known as the change in the chemical composition of bitumen resulted from reaction with oxygen. Third factor known as steric hardening is molecular structuring that produces thixotropic effects. Among these factors, oxidation is mainly considered as a major factor contributing in the hardening of the asphalt pavement.

The literature review shows that aging of asphalt occurs in two terms called short- and long-term respectively [9]. Shortterm aging occurs during mixing and final placement when the asphalt is at elevated temperatures. This is probably caused by volatilization. Long-term aging occurs partially throughout the short-term aging frame and while the asphalt is in service and exposed to the environment [10]. This long-term aging is predominantly caused by oxidation. Aging of asphalt may be influenced simultaneously by several factors, such as characteristics and content of the bitumen, nature and particle size and distribution of the aggregates, void content of the mixture, production related factors, and external conditions such as temperature and time [11]. Asphalt additives would considerably change the mixture characteristics. Beside the effect of modification in bitumen, it can intuitively be expected that a WMA pavement would be less subjected to aging than an HMA pavement in construction and hauling phases since the application temperatures of WMA pavement are relatively lower than application temperatures of HMA pavements. Beside this, the modifying effects of WMA additives on base bitumen can have other side effects on the bitumen microstructure which may cause less or more durability during the service life of the pavement. This study attempts to investigate the rate of hardening by adding the various amounts of different WMA additives into the base bitumen. To define the micro effects of these additives on chemical and inter- nal properties of the base bitumen, further investigations should be carried out distinctly. More investigation can help the understanding of the micro mechanism of different aging processes and the effect of WMA additives on each process.

\section{Experimental}

\subsection{Materials}

The bitumen used in this study was $50 / 70$ penetration grade bitumen which was provided from Aliaga/Izmir Oil Terminal of the Turkish Petroleum Refinery Corporation. This grade of penetration is commonly used in Izmir/Turkey due to climatic conditions. Conventional test results such as penetration test, softening point test, ductility test and etc. conducted in conformity with the relevant test methods are given in Table 1 .

The aggregates used in this study consist of a mix of basalt and limestone aggregates provided from Dere Madencilik Inc. quarry located in Belkahve/Izmir. The properties of the aggregate were investigated by several tests such as specific gravity, Los Angeles abrasion resistance, sodium sulfate soundness, fine aggregate angularity and flat and elongated particles. Test results conducted on both aggregate types are presented in Table 2

The mix gradation of basalt and limestone was intentionally chosen to provide desired performance in conformity with Turkish specifications concerning the Type 1 wearing course. Basalt plays the role of strengthening constituent as coarse aggregate while limestone participates in the fine aggregate framework. Table 3 presents the final gradation chosen for basalt-limestone aggregate mixture.

The organic WMA additive used within the scope of this study was supplied from a South African company. This organic WMA additive is a long-chain aliphatic polymethlene hydrocarbon with approximate melting point of $120^{\circ} \mathrm{C}$. It is completely soluble in bitumen at temperatures above $140^{\circ} \mathrm{C}$. This organic additive is produced by coal gasification using the FischerTropsch (FT) synthetic process. The longer chains help keep the wax in solution, which reduces the bitumen viscosity at typical asphalt production and compaction temperatures. The organic WMA additive concentrations in the base bitumen were chosen as $2-4 \%$. The utilization of these contents is based on previous researches [12-14].

Chemical WMA additive, which has been used in this study, is a combination of both organic additive and a kind of cationic surfactant [15]. The surfactants simply increase the coating ability of the aggregate with the bitumen by "active adhesion." while the other constituents participate in reducing the viscosity of the bitumen [16]. Use of this chemical additive can reduce the production temperature by about 10 to $15^{\circ} \mathrm{C}$ and consequently can result in a $20 \%$ reduction in fuel consumption [4, 16]. Literature reviews indicated that the chemical WMA additive should be used at dosage rates of $1-3 \%$ by weight of the bitumen for better performance of mixture [15, 17, 19].

There are various types of water-containing additives on the market. In this study, hydro-thermally crystallized powdered 
Tab. 1. The properties of the base bitumen

\begin{tabular}{|c|c|c|c|}
\hline Test & Test Method & Results & Specification Limits \\
\hline Penetration $\left(25^{\circ} \mathrm{C} ; 0.1 \mathrm{~mm}\right)$ & ASTM D5 & 63 & $50-70$ \\
\hline Softening Point $\left({ }^{\circ} \mathrm{C}\right)$ & ASTM D36 & 49 & $46-54$ \\
\hline Viscosity at $\left(135^{\circ} \mathrm{C}\right)$ - Pa.s & ASTM D4402 & 0.51 & - \\
\hline Thin Film Oven Test (TFOT) & ASTM D1754 & & \\
\hline Change of mass $(\%)$ & & 0.07 & $0.5(\max )$ \\
\hline Retained penetration (\%) & ASTM D5 & 51 & 50 (min) \\
\hline Softening Point after TFOT $\left({ }^{\circ} \mathrm{C}\right)$ & ASTM D36 & 51 & - \\
\hline Ductility $\left(25^{\circ} \mathrm{C}\right), \mathrm{cm}$ & ASTM D113 & 100 & - \\
\hline Specific Gravity & ASTM D70 & 1.030 & - \\
\hline Flash Point $\left({ }^{\circ} \mathrm{C}\right)$ & ASTM D92 & +260 & 230 (min) \\
\hline
\end{tabular}

Tab. 2. The properties of the both basalt and limestone aggregates

\begin{tabular}{|c|c|c|c|c|}
\hline \multirow{2}{*}{ Test } & \multirow{2}{*}{ Specification } & \multicolumn{2}{|c|}{ Result } & \multirow{2}{*}{$\begin{array}{c}\text { Specification } \\
\text { Limit }\end{array}$} \\
\hline & & Limestone & Basalt & \\
\hline $\begin{array}{c}\text { Specific Gravity (Coarse } \\
\text { Agg.) }\end{array}$ & ASTM C 127 & & & \\
\hline Bulk & & 2.686 & 2.666 & - \\
\hline SSD & & 2.701 & 2.810 & - \\
\hline Apparent & & 2.727 & 2.706 & - \\
\hline Specific Gravity (Fine Agg.) & ASTM C 128 & & & \\
\hline Bulk & & 2.687 & 2.652 & - \\
\hline SSD & & 2.703 & 2.770 & - \\
\hline Apparent & & 2.732 & 2.688 & - \\
\hline Specific Gravity (Filler) & & 2.725 & 2.731 & - \\
\hline Los Angeles Abrasion (\%) & ASTM C 131 & 24.4 & 14.2 & $\max 45$ \\
\hline $\begin{array}{c}\text { Flat and Elongated } \\
\text { Particles (\%) }\end{array}$ & ASTM D 4791 & 7.5 & 5.5 & $\max 10$ \\
\hline $\begin{array}{l}\text { Sodium Sulfate Soundness } \\
\qquad(\%)\end{array}$ & ASTM C 88 & 1.47 & 2.6 & $\max 10-20$ \\
\hline Fine Aggregate Angularity & ASTM C 1252 & 47.85 & 58.1 & $\min 40$ \\
\hline
\end{tabular}

synthetic zeolite has been used which is manufactured in North America by PQ Corporation. It contains about 18-21\% water within its micro pores which can be released by increasing temperature above $85^{\circ} \mathrm{C}$. The expansion of water causes foaming of bitumen. The recommended amount of use is $0.25 \%$ by total weight of the mix [12]. The additive contents used in this study range from 4 to $6 \%$ by weight of the binder which was chosen based on the previous studies.

Natural zeolite which can be considered as an alternative to synthetic zeolite WMA additive was supplied from a Turkish local company in powder form. It has the complex formula: $\left(\mathrm{Na}_{3} \mathrm{~K}_{3}\right)\left(\mathrm{Al}_{6} \mathrm{Si}_{30} \mathrm{O}_{72}\right) 27 \mathrm{H}_{2} \mathrm{O}$. It forms as white to reddish tabular monoclinic tectosilicate crystals with a Mohs hardness of $3.5-4.0$ and a specific gravity of $2.1-2.2$. The content of natural zeolite in this study has been chosen as $4-6 \%$ by weight of bitumen so as to compare its fundamental characteristics with synthetic zeolite. The properties of natural zeolite are presented in Table 4

\subsection{Determination of modification temperature and period for WMA additives}

The optimum modification period and temperature are important factors attributable to preserving bitumen from aging during the modification process. Modification temperatures and periods were determined based on a trial and error method considering no change in viscosity values. The idea is that when a constant viscosity is achieved after modification process, it can be concluded that a homogenous modified bitumen is obtained. In this method, after adding the specified amount of additive to the bitumen, stirring was started at the assigned temperature for a definite period of time. After the modification process was over, the viscosity of the new WMA bitumen was determined by a rotational viscometer (ASTM D4402-12). This process was repeated several times at a constant temperature for different period of times as well as at altered temperatures for a fixed period of time. By tabulation of viscosity values under different temperatures and mixing periods, the border that the viscosity remained constant was chosen as the optimum modification period and temperature. In this context, the optimum modification periods and temperatures were determined as $10 \mathrm{~min} . \& 120^{\circ} \mathrm{C}$ for organic, $15 \mathrm{~min} . \& 150^{\circ} \mathrm{C}$ for chemical and $20 \mathrm{~min} . \& 120^{\circ} \mathrm{C}$ 
Tab. 3. Gradation for basalt - limestone aggregate mixture

\begin{tabular}{|c|c|c|c|c|c|}
\hline Test & $19-12.5 \mathrm{~mm}$ (Basalt) & $12.5-5 \mathrm{~mm}$ (Basalt) & 5-0 mm (Limestone) & $\begin{array}{c}\text { Combined Gradation } \\
\qquad(\%)\end{array}$ & $\begin{array}{l}\text { Specification Limit } \\
\text { (Turkish Highways } \\
\text { Technical Provisions) }\end{array}$ \\
\hline \multicolumn{6}{|l|}{ Sieve No } \\
\hline $3 / 4 "$ & 100 & 100 & 100 & 100 & 100 \\
\hline $1 / 2 "$ & 35.7 & 100 & 100 & 90.5 & $83-100$ \\
\hline $3 / 8 "$ & 2.5 & 89 & 100 & 80.5 & $70-90$ \\
\hline No 4 & 0.4 & 16 & 100 & 47.3 & $40-55$ \\
\hline No 10 & 0.3 & 1.2 & 81 & 33 & $25-38$ \\
\hline No 40 & 0.2 & 0.7 & 33 & 13.5 & $10-20$ \\
\hline No 80 & 0.15 & 0.4 & 22 & 9 & $6-15$ \\
\hline No 200 & 0.10 & 0.2 & 13 & 5.3 & $4-10$ \\
\hline
\end{tabular}

Tab. 4. Physical properties and chemical structure of natural zeolite

\begin{tabular}{|c|c|c|c|c|c|c|c|c|c|c|c|}
\hline \multicolumn{12}{|c|}{ Chemical Structure } \\
\hline $\mathrm{SiO} 2$ & $\mathrm{Al} 2 \mathrm{O} 3$ & $\mathrm{Fe} 2 \mathrm{O} 3$ & $\mathrm{~K} 2 \mathrm{O}$ & $\mathrm{H} 2 \mathrm{O}$ & $\mathrm{CaO}$ & $\mathrm{MgO}$ & $\mathrm{Na} 2 \mathrm{O}$ & $\mathrm{Ti}$ & $\mathrm{Ag}$ & $\mathrm{N}$ & $\mathrm{B}(\mathrm{ppm})$ \\
\hline$(71.29$ & 13.55 & 1.15 & 3.5 & 5.9 & 1.96 & 0.7 & 0.6 & 0.02 & 0.04 & & 30 \\
\hline \multicolumn{12}{|c|}{ Physical Properties } \\
\hline \multicolumn{2}{|c|}{ Voids (\%) } & \multicolumn{4}{|c|}{ Dimensions of the Main Channels $(\mathrm{A})$} & \multicolumn{3}{|c|}{ Thermal Stability } & \multicolumn{3}{|c|}{ Ion Exchange Capacity (meq/g) } \\
\hline \multicolumn{2}{|c|}{34} & \multicolumn{4}{|c|}{$3.9 \times 5.4$} & \multicolumn{3}{|c|}{ High } & \multicolumn{3}{|c|}{2.16} \\
\hline
\end{tabular}

for both synthetic and natural zeolite WMA additives.

\subsection{Preparation of bitumen samples containing WMA addi- tives}

Following the determination of optimum modification temperatures and periods, the WMA bitumen samples were prepared by means of a high shear laboratory stirrer rotating at $1100 \mathrm{rpm}$. The base bitumen was heated to fluid condition $\left(120^{\circ} \mathrm{C}\right)$ and poured into a $2000 \mathrm{ml}$ spherical flask. After reaching to desired modification temperature the WMA additives were added gradually to the base bitumen and the stirring was done for a period of determined optimum modification time. In case of foaming additives, although the release of tiny steam bubbles continues for a period of several hours, the greatest, part of foaming phenomenon occurs instantly after adding the foaming additive. Therefore, it is recommended that the bitumen containing synthetic or natural zeolite be directly used following the modification process.

\subsection{Test methods}

\subsubsection{Conventional bitumen tests}

The base bitumen and bitumen prepared with WMA additives were subjected to the following conventional bitumen tests; penetration (ASTM D5-06), ring and ball softening point (ASTM D36-95), Thin Film Oven Test (TFOT) (ASTM D1754M-09), Rolling Thin Film Oven Test (RTFOT) (ASTM D2872-12), penetration and softening point after TFOT and storage stability test (EN 13399) [20-24]. In addition, the temperature susceptibility of the bitumen samples was calculated in terms of penetration index (PI) using the results obtained from penetration and soft- ening point tests. The storage stability value was determined by the difference of softening point temperatures of bitumen samples taken from the top and bottom of cylindrical mold $(32 \mathrm{~mm}$ diameter and $160 \mathrm{~mm}$ height) after they were stored vertically at $163^{\circ} \mathrm{C}$ in an oven for $72 \mathrm{~h}$.

\subsubsection{Determination of mixing and compaction tempera- tures}

Brookfield viscometer has been employed to measure the viscosity of bitumen according to ASTM D4402-12 [25]. Approximately $30 \mathrm{~g}$ of bitumen was heated in an oven so that it was sufficiently fluid to pour into the sample chamber. The amounts of bitumen used varied with the different sizes of the spindles. The sample chamber containing the bitumen sample was then placed inside the thermo container. After the desired temperature has been stabilized for about $15 \mathrm{~min}$, the spindle was lowered into the chamber to test the viscosity. The test was performed at $135^{\circ} \mathrm{C}$ and $165^{\circ} \mathrm{C}$. After determining the viscosity values, mixing and compaction temperatures for the base and WMA bitumens were derived from viscosity - temperature charts in accordance with ASTM D2493-09 [26]. The experimental curves were plotted for base and WMA bitumens. Curves for various bitumen types are presented in Fig. 1. Acceptable equiviscous bitumen temperatures for mixing was chosen as the range corresponding to $0.17 \pm 0.02 \mathrm{~Pa}$.s and acceptable temperatures for compaction was chosen as the range matching $0.28 \pm 0.03$ Pa.s.

\subsubsection{Preparation of the bituminous mixtures}

Following the production of WMA modified bitumens, WMA mixtures were prepared based on the determined mixing temper- 


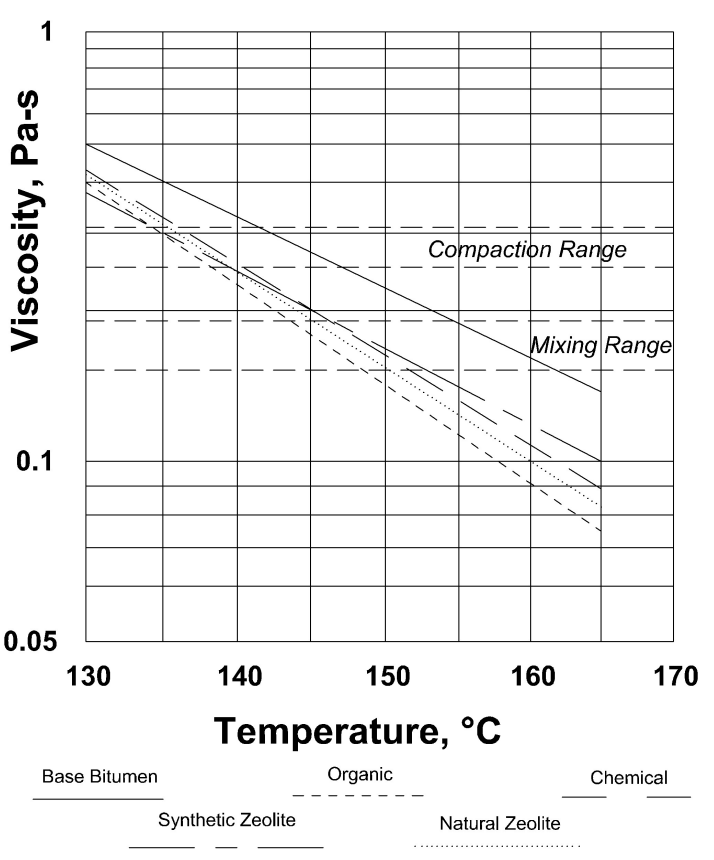

Fig. 1. Viscosity-temperature chart for base and WMA involving bitumens

atures. The industrial mixer was used for mixing the aggregates and the bitumen. The optimum bitumen content was determined by the Marshall mix design method. The bitumen content corresponding $4 \%$ air voids was selected and then the other values were ensured based on specification limits indicated within Turkish highways technical provisions. The optimum bitumen content for the base and WMA bitumens were determined as $4.76 \%$ for base bitumen, $4.25 \%$ for organic, $4.46 \%$ for chemical, $4.32 \%$ for synthetic zeolite and $4.56 \%$ for natural zeolite modified bitumens by weight of the aggregates. The aggregates were placed in an oven adjusted for proper temperature the day before being completely dried and ready for mixing. Specimens were compacted with Marshall compactor regarding their compaction temperatures after mixing process. Conditioning as per AASHTO R 30 [27] standard process were done on the specimens intended to be aged. Short-term aged specimens were conditioned in a forced draft oven set for $135^{\circ} \mathrm{C}$ for $4 \mathrm{~h}$ and then compacted and cured since the long-term aged specimens were conditioned for 124 hours in a forced draft oven set for $85^{\circ} \mathrm{C}$ after passing the short-term aging conditions. All processes regarding conditioning of the mixtures are shown on a flowchart in Fig. 2

\subsubsection{Determination of the indirect tensile strengths (ITS) of bituminous mixtures}

All specimens were tested for indirect tensile strength (ITS) after being cured. To perform this task, ASTM D6931-12 standard test method was taken into account [28]. The ITS test was conducted by Marshall stability and flow apparatus. The loading rate was set to $51(\mathrm{~mm} / \mathrm{min})$ in case for ITS. To be adequate and unbiased, three specimens for each WMA mixture were prepared and tested randomly. The Indirect Tensile Strength (ITS) values can give an evaluation key in terms of low temperature and fatigue cracking of bituminous mixtures. Some studies introduce ITS result as a good indicator in predicting the laboratory rutting potential of asphalt mixtures [29]. The ITS test is widely used in investigation of moisture susceptibility of bituminous mixtures.

When evaluating the aging characteristics, as the bitumen ages, it becomes more brittle and stiffer, thus the ITS results of an aged mixture are rather more than the results of an unaged mixture. This fact can simply provide aging indices to investigate the aging characteristics of bituminous mixtures. Sengoz [30] has implemented ITS results of mixtures with various air voids, to assess aging and moisture susceptibility characteristics of HMA mixtures. Another study on short- and long-term aging behavior of rubber modified asphalts conducted by Liang and Lee [31] has also proved the fact that the short- and longterm aging conditioning increase the measured tensile strengths. Sengoz and Topal [32] investigated the effects of SBS polymer modified bitumen on the aging properties of bituminous mixtures using ITS results. They calculated aging indices as the ratio of short- and long-term aged specimen's ITS values to the values of unaged control specimens prepared with the same additive content. Hurley and Prowell [33] used ITS results to check the rutting potential after application and the short- and longterm aging characterization of WMA mixes containing organic WMA additive.

The raw data recorded from the test device should be processed using the following Eq. (1) to obtain ITS values:

$$
S_{t}=(2000 \times P) /(\pi \times t \times D)
$$

Where;

$S_{t} \quad$ Indirect tensile strength (ITS), $\mathrm{kPa}$

$P \quad$ Maximum load, $\mathrm{N}$

$t \quad$ Specimen height immediately before test, $\mathrm{mm}$

D Specimen diameter, $\mathrm{mm}$

\section{Results and discussions}

\subsection{Conventional bitumen test results}

The conventional properties of the bitumen prepared with organic, chemical and water containing additives (natural and synthetic zeolites) are presented in Table 5 as a decrease in penetration and increase in softening point.

The increase in softening point is favorable since bitumen with higher softening point may be less susceptible to permanent deformation (rutting) [34]. Organic, chemical, synthetic and natural zeolite (for all contents) WMA additives potentially reduce temperature susceptibility (as determined by the penetration index-PI) of the bitumen. Lower values of PI indicate higher temperature susceptibility. As seen in Table 5, all WMA samples exhibit less temperature susceptibility compared to base bitumen with increasing WMA additive content. Natural zeolite 


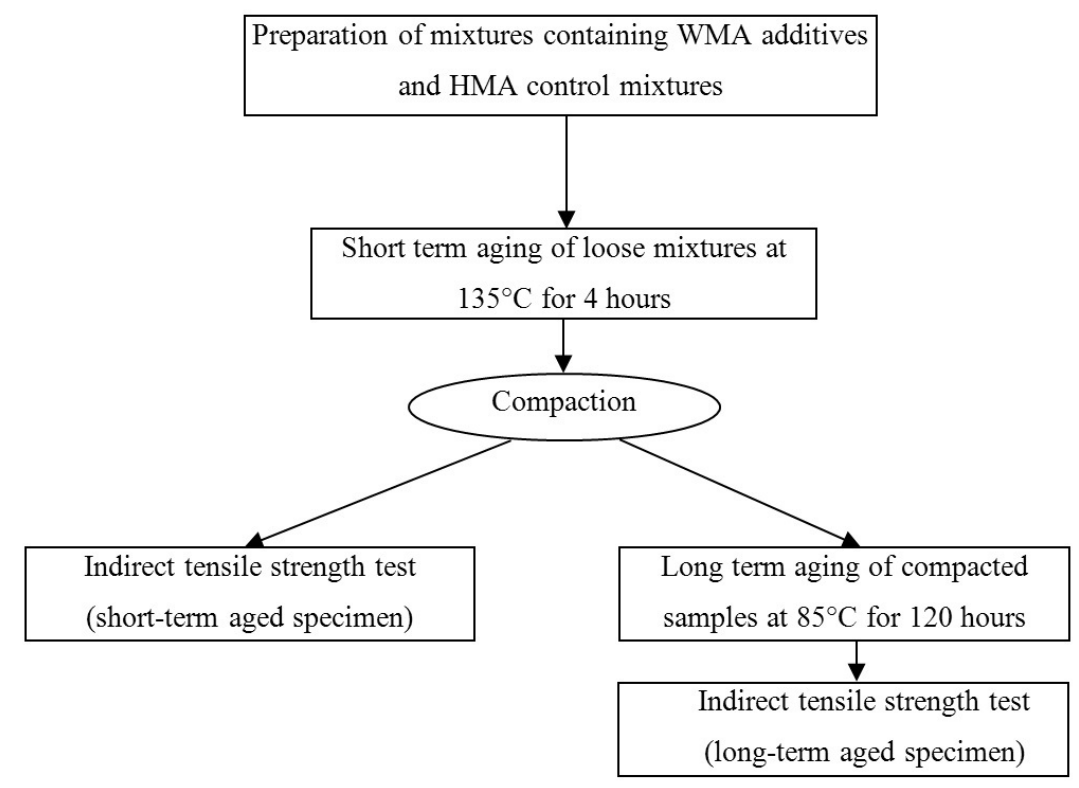

Fig. 2. Short- and long-term conditioning flowchart

involving bitumen sample exhibits satisfactory temperature susceptibility characteristics in terms of PI values as presented in Table 5 . Besides among all the additives, the bitumen involving organic additive exhibits the lowest temperature susceptibility. Organic additive can be used in areas having wide range of climate change since the bitumen modified with this wax sustains its rheological properties in good conditions while having increased softening point. Asphalt mixtures containing bitumen with higher PI are more resistant to low temperature cracking as well as permanent deformation [34]. Softening point test results on bitumen samples prepared with WMA additives taken from the top and bottom of the tube in the storage stability test indicate that, both natural and synthetic zeolite involving bitumen samples exhibit similar storage stability characteristics as presented in Table 5. Besides, the bitumen samples prepared with chemical additives are much more storage stable compared to other WMA involving samples. The storage stability value was determined by the difference of softening point temperatures of bitumen samples taken from the top and bottom of cylindrical mold ( $32 \mathrm{~mm}$ diameter and $160 \mathrm{~mm}$ height) after they were stored vertically at $163^{\circ} \mathrm{C}$ in an oven for $72 \mathrm{~h}$.

\subsection{Mixing and compaction temperatures}

The viscosity values of samples involving WMA additives are also seen in Table 5. Related to bitumen samples involving natural and synthetic zeolites, the viscosity values decrease with the increase in zeolite content up to $5 \%$ and decrease thereon as presented in Table 5 Therefore, based on the viscosity data, $5 \%$ can be evaluated as optimum for both natural and synthetic zeolite content. The results also show a consistent decrease in viscosity by the increase in WMA content of organic and chemical WMA additives. This indicates that, all organic and chemical WMA additives increase the workability and make relatively reductions for mixing and compaction temperatures.
The temperatures corresponding to compaction and mixing ranges are given in Table 6 . Considering the upper levels of temperature ranges, it is evident that the mixing and compaction temperatures are lowered respectively by $15^{\circ} \mathrm{C}$ and $12^{\circ} \mathrm{C}$ (by addition of $\% 3$ organic additive), $12^{\circ} \mathrm{C}$ and $9^{\circ} \mathrm{C}$ (by addition of $2 \%$ chemical additive), ${ }^{\circ} 11 \mathrm{C}$ and $9^{\circ} \mathrm{C}$ (by addition of $5 \%$ synthetic zeolite additive) and lastly $13^{\circ} \mathrm{C}$ and $10^{\circ} \mathrm{C}$ (by addition of $5 \%$ natural zeolite additive). Upper limits were exactly taken into account during laboratory tests in order to compensate temperature drops in laboratory conditions.

The results of the research indicated that the addition of WMA additives decreased the mixing and compaction temperatures of the mixtures. It should be mentioned here that although the temperature reduction is determined by way of viscosity test [25] performed on the bitumen samples involving zeolites; the filler like structure of zeolite within the base bitumen is very delicate affecting the viscosity values. The ASTM standard regarding viscosity test [25] indicates the following statements in the case of determination of a bitumen involving filler like structure:

The single-operator precision (repeatability) standard deviation has been determined to be $21 \%$. Therefore, two results obtained in the same laboratory, by the same operator using the same equipment, in the shortest practical period of time, should be considered not equivalent if the difference in the two results, expressed as a percent of their mean, exceeds $59.4 \%$.

The multilaboratory precision (reproducibility) standard deviation has been determined to be $33.2 \%$. Therefore, two results submitted by two different operators testing the same material in different laboratories shall be considered not equivalent if the difference in the two results, expressed as a percent of their mean, exceeds $94.0 \%$.

As can be seen, the repeability of the viscosity test regard- 
Tab. 5. Conventional properties of bitumen prepared with warm mix asphalt

\begin{tabular}{|c|c|c|c|c|c|c|c|c|c|c|c|c|}
\hline \multirow[b]{2}{*}{ Additives } & \multirow[b]{2}{*}{$\begin{array}{c}\text { Contents } \\
(\%)\end{array}$} & \multirow[b]{2}{*}{$\begin{array}{c}\text { Pen. } \\
(0.1 \mathrm{~mm})\end{array}$} & \multirow[b]{2}{*}{$\begin{array}{l}\text { Softening } \\
\text { Point }\left({ }^{\circ} \mathrm{C}\right)\end{array}$} & \multicolumn{2}{|c|}{ Viscosity (mPa.s) } & \multicolumn{3}{|c|}{ Thin Film Oven Test (TFOT) } & \multicolumn{4}{|c|}{ Rolling Thin Film Oven Test (RTFOT) } \\
\hline & & & & $135^{\circ} \mathrm{C}$ & $160^{\circ} \mathrm{C}$ & $\begin{array}{l}\text { Loss of } \\
\text { mass(\%) }\end{array}$ & $\begin{array}{l}\text { Retained } \\
\text { Pen.(\%) }\end{array}$ & $\begin{array}{l}\text { Soft.Point } \\
\text { diff. }\left({ }^{\circ} \mathrm{C}\right)\end{array}$ & $\begin{array}{l}\text { Loss of } \\
\text { mass(\%) }\end{array}$ & $\begin{array}{l}\text { Retained } \\
\text { Pen.(\%) }\end{array}$ & $\begin{array}{l}\text { Soft.Point } \\
\text { diff. } \\
\left({ }^{\circ} \mathrm{C}\right)\end{array}$ & $\begin{array}{l}\text { Pen. } \\
\text { Index }\end{array}$ \\
\hline \multirow{4}{*}{ Organic } & 0 & 55 & 49.1 & 412.5 & 137.5 & 0.04 & 25 & 5.0 & -0.04 & 26 & 5.3 & -1.20 \\
\hline & 2 & 43 & 61.2 & 300.0 & 112.0 & 0.07 & 14 & 4.3 & -0.07 & 16 & 4.5 & 0.89 \\
\hline & 3 & 37 & 69.3 & 287.5 & 75.0 & 0.07 & 13 & 4.0 & -0.07 & 15 & 4.3 & 1.95 \\
\hline & 4 & 31 & 79.5 & 275.0 & 75.0 & 0.08 & 6 & 2.5 & -0.08 & 10 & 3.5 & 3.07 \\
\hline \multirow{4}{*}{ Chemical } & 0 & 55 & 49.1 & 412.5 & 137.5 & 0.04 & 25 & 5.0 & -0.04 & 26 & 5.3 & -1.20 \\
\hline & 1 & 48 & 55.4 & 350.0 & 113.0 & 0.06 & 19 & 3.4 & -0.06 & 22 & 3.6 & -0.04 \\
\hline & 2 & 44 & 56.7 & 337.5 & 87.5 & 0.04 & 16 & 2.5 & -0.07 & 17 & 2.5 & 0.04 \\
\hline & 3 & 40 & 58.0 & 287.5 & 75.0 & 0.06 & 13 & 1.5 & -0.08 & 17 & 2.1 & 0.09 \\
\hline \multirow{6}{*}{$\begin{array}{l}\text { Synthetic } \\
\text { Zeolite }\end{array}$} & 0 & 55 & 49.1 & 412.5 & 137.5 & 0.04 & 25 & 5.0 & -0.04 & 26 & 5.3 & -1.20 \\
\hline & 3 & 55 & 53.1 & 350.0 & 138.0 & 0.15 & 18 & 4.9 & -0.16 & 23 & 5.0 & -0.26 \\
\hline & 4 & 53 & 53.6 & 325.0 & 125.0 & 0.15 & 17 & 4.7 & -0.17 & 21 & 4.8 & -0.22 \\
\hline & 5 & 52 & 56.0 & 312.5 & 112.5 & 0.16 & 16 & 4.1 & -0.18 & 21 & 4.5 & 0.27 \\
\hline & 6 & 45 & 59.9 & 437.5 & 150.0 & 0.16 & 11 & 3.3 & -0.18 & 14 & 3.7 & 0.74 \\
\hline & 7 & 43 & 61.2 & 512.5 & 175.0 & 0.17 & 10 & 3.2 & -0.18 & 13 & 3.2 & 0.87 \\
\hline \multirow{6}{*}{$\begin{array}{l}\text { Natural } \\
\text { Zeolite }\end{array}$} & 0 & 55 & 49.1 & 412.5 & 137.5 & 0.04 & 25 & 5.0 & -0.04 & 26 & 5.3 & -1.20 \\
\hline & 3 & 54 & 53.6 & 362.5 & 162.5 & 0.16 & 18 & 4.1 & -0.16 & 22 & 4.4 & -0.16 \\
\hline & 4 & 53 & 54.1 & 350.0 & 125.5 & 0.16 & 17 & 4.0 & -0.17 & 18 & 4.3 & -0.10 \\
\hline & 5 & 51 & 55.0 & 325.0 & 113.0 & 0.16 & 15 & 3.7 & -0.17 & 17 & 3.7 & 0.02 \\
\hline & 6 & 45 & 58.2 & 400.0 & 187.5 & 0.17 & 10 & 3.5 & -0.17 & 15 & 3.2 & 0.40 \\
\hline & 7 & 42 & 59.2 & 487.5 & 187.5 & 0.17 & 10 & 3.2 & -0.17 & 13 & 3.0 & 0.44 \\
\hline
\end{tabular}

ing filler like structure involving bitumen is low. Therefore it is recommended that the zeolites be added into the mixture rather than base bitumen and the temperature reduction should be determined through the compacted mixture at different temperature levels by taking the final density of the compacted specimen into account and comparing with the density of actual HMA.

\subsection{Indirect tensile strength (ITS) test results of bituminous mixtures}

The ITS results of unaged, short- and long-term aged specimens for organic, chemical, synthetic zeolite and natural zeolite WMA additives are respectively given in Figures 3 - 6. In these figures, additive content corresponding 0 simply demonstrates the HMA control specimens.

The results of unaged specimens indicate that using nonfoaming WMA additives (organic and chemical) can potentially increase the indirect tensile strength of asphalt specimens. This fact is observable in additive contents more than $3 \%$ for organic additive and $2 \%$ for chemical additive respectively. The higher ITS values in case of unaged specimens for chemical additive points out the specimens strength in terms of internal bonds. For both non-foaming additives, since they seem to soften the mixture at the first level of additive content, the use of higher contents of these additives strengthens the internal bonds of the mixtures in terms of tensile strength. In case of chemical additive, this fact is in conformity with the statement of Prowell and Hurley [35] and Lai and Tsai [16] that all stated about the "active adhesion" which plays role in increasing the coating abil- ity of the aggregate with the bitumen by means of surfactants and consequently can result in higher internal bonds. In case of foaming additives, internal bonds are adversly affected by water content remaining from application process. Although this water content evaporates in several days after compaction process, its adverse impress on adhesion of mix should not be ignored.

Specimens involving foaming additives (synthetic and natural zeolites) both exhibit lower ITS values than HMA specimens. This can be explained as these foaming additives may cause the stripping phenomenon in mixture since the moisture directly affects the adhesion between aggregates and the bitumen. Therefore the use of foaming additives potentially weakens the bituminous mixture in terms of tensile strength.

Aging indices can provide better evaluation to understand the effects of WMA additives on aging characteristics of bituminous mixtures. In this study, these indices were calculated as the ratio of ITS values of short- and long-term aged specimens over ITS values of HMA control specimens. The calculating equations for the short-term aging index (SAI) and long-term aging index (LAI) are given in Eq. (2) and Eq. (3) respectively.

$$
\begin{aligned}
& S A I=\frac{(\text { ITS valueof short }- \text { termaged specimen })}{(\text { ITS valueofunagedspecimen })} \\
& L A I=\frac{(\text { ITS valueoflong }- \text { termagedspecimen })}{(\text { ITS valueofunagedspecimen })}
\end{aligned}
$$

By means of these indices, it is more understandable to observe how hardened an aged specimen has become after the aging process. The less an aging index of a mixture is, the more 


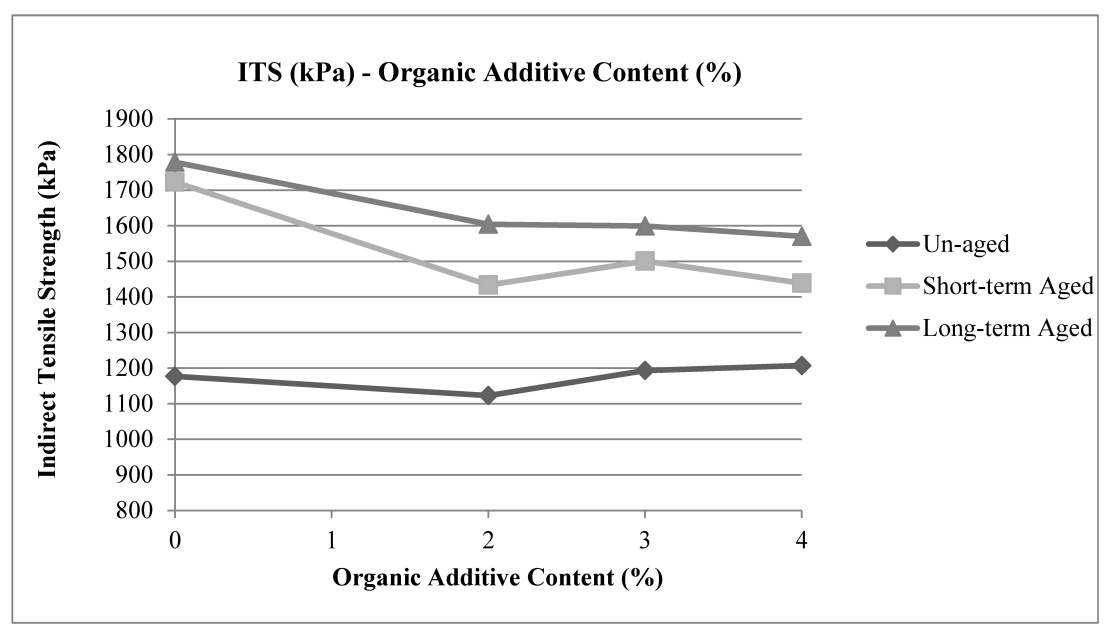

Fig. 3. ITS results corresponding to organic additive contents

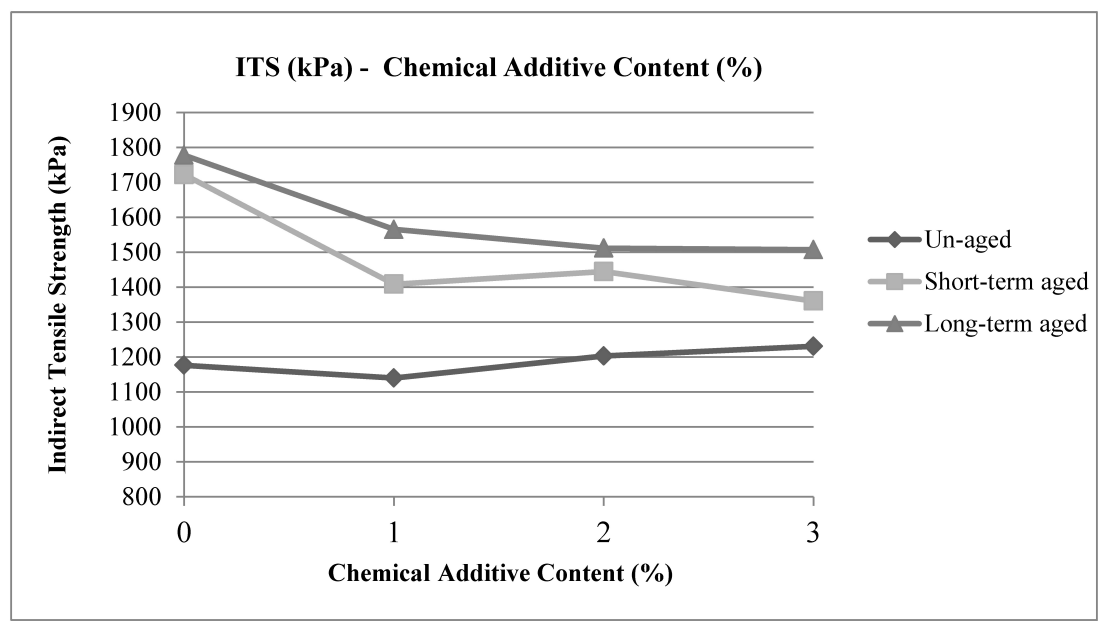

Fig. 4. ITS results corresponding to chemical additive contents

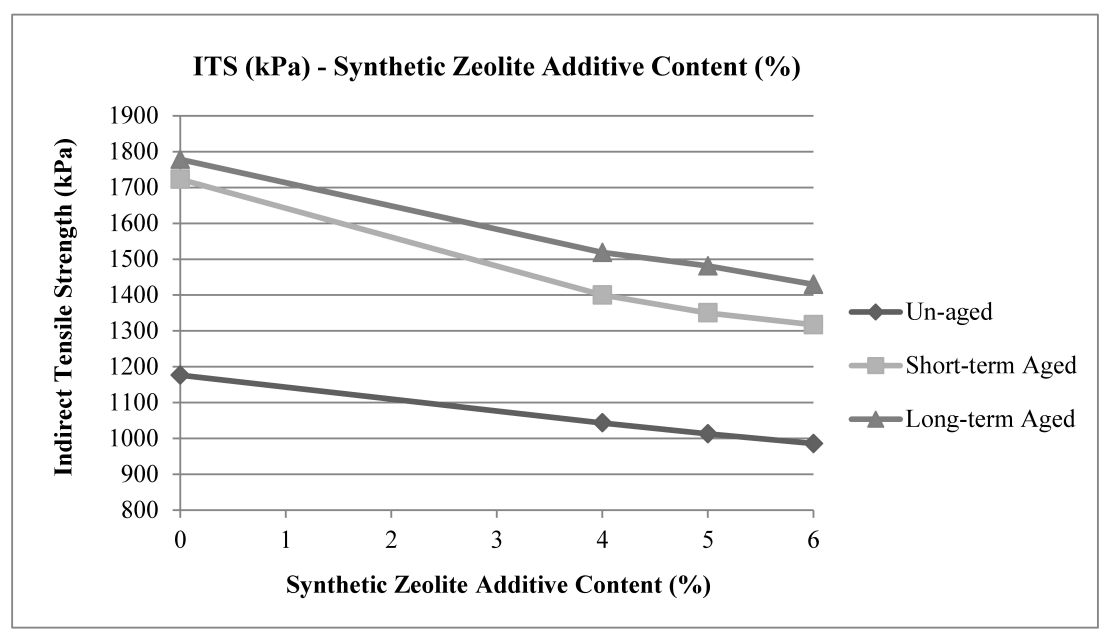

Fig. 5. ITS results corresponding to synthetic zeolite additive contents 
Tab. 6. Mixing and compaction temperatures of WMA additives

\begin{tabular}{cccc}
\hline Additives & Contents $(\%)$ & Mixing Temp. $\left({ }^{\circ} \mathrm{C}\right)$ & Compaction Temp. $\left({ }^{\circ} \mathrm{C}\right)$ \\
\hline Base Bitumen $(50 / 70)$ & 0 & $156-163$ & $143-149$ \\
\hline \multirow{2}{*}{ Organic } & 2 & $149-156$ & $134-140$ \\
& 3 & $143-148$ & $133-137$ \\
Chemical & 4 & $144-149$ & $132-137$ \\
& 1 & $151-157$ & $138-144$ \\
& 2 & $147-151$ & $136-140$ \\
Synthetic Zeolite & 3 & $144-150$ & $133-138$ \\
\hline \multirow{2}{*}{ Natural Zeolite } & 4 & $152-159$ & $136-143$ \\
& 5 & $147-152$ & $135-140$ \\
& 6 & $158-165$ & $145-151$ \\
\hline & 4 & $153-156$ & $139-142$ \\
\hline
\end{tabular}

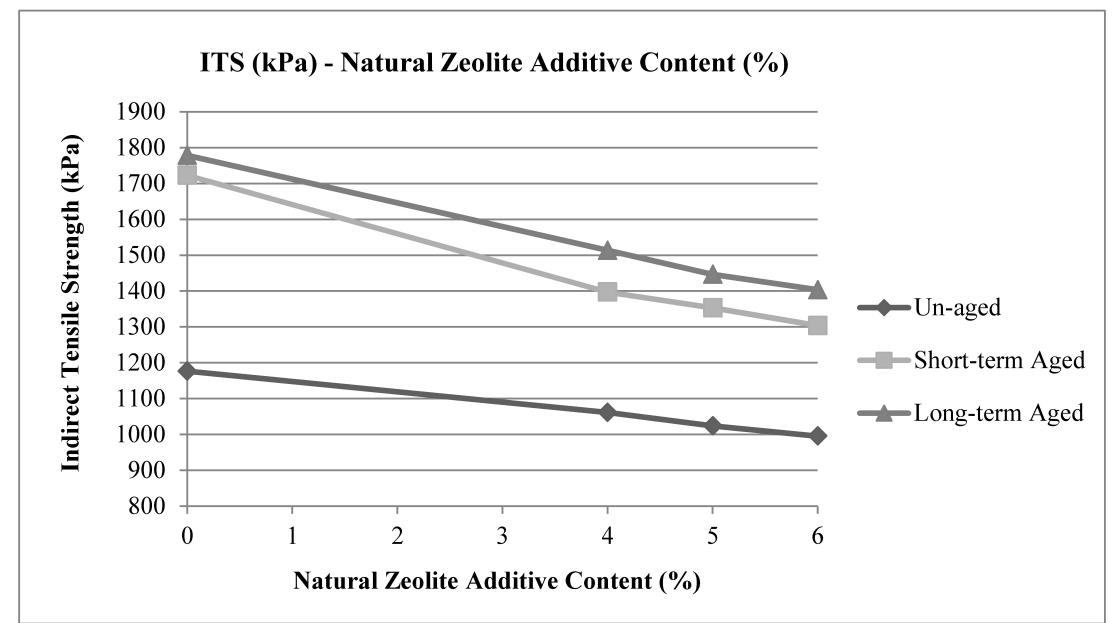

Fig. 6. ITS results corresponding to natural zeolite additive contents

resistive that mixture is against hardening. The SAI and LAI values for organic, chemical, synthetic zeolite and natural zeolite WMA additives are respectively demonstrated in Figures $7-10$.

As seen in the Figures 7 - 10, almost all WMA specimens exhibited lower aging indices than control specimens. This situation was an expected case since the application temperatures for WMA technologies are lower than the application temperatures for HMA technology. Temperature is a vital factor in occasion of the aging. Lower application temperatures can cause less aging especially in case of short-term aging during mixing and compaction phases of pavement construction since the long-term conditions may be equal for both WMA and HMA mixtures during the service life of the pavements. This fact was considered in artificially long-term conditioning of both WMA and HMA mixtures. Although the short-term aging simulation at $135^{\circ} \mathrm{C}$ was the same for both WMA and HMA mixtures, the SAI values indicate that the rate of aging during mixing and compaction phases in laboratory affect the rate of overall shortterm aging to large extents. Besides, the effect of WMA additives on internal properties of bitumen may be the case. In this context, further investigation should be conducted to understand the aging mechanism more comprehensively. Having a glance on the slope of the trendlines for both SAI and LAI values in all the aging graphs, it is evident that the drop in SAI is more than the drop in LAI for all the additives. The short-term aging occurs during production, storage, hauling and compaction phases at particular temperatures.

SAI and LAI values unveiled that non-foaming additives (organic and chemical) acted better than foaming additives (synthetic and natural zeolites) in terms of aging. This is attributed when considering the temperature drop for non-foaming and foaming additives as non-foaming additives acted better than foaming additives. Also internal bonds affect ITS test result. When discussing about foaming additives (synthetic and natural zeolites), although they demonstrated less indices than HMA mixture, the reduction in hardening was not sensible for these additives in comparison with non-foaming additives (organic and chemical). Comparing two foaming additives, samples involving natural zeolite exposed lower aging indices than samples containing synthetic zeolite. Increasing the additive content does not have a considerable effect on aging indices in case of foaming additives.

Chemical WMA additive demonstrated the best resistance 


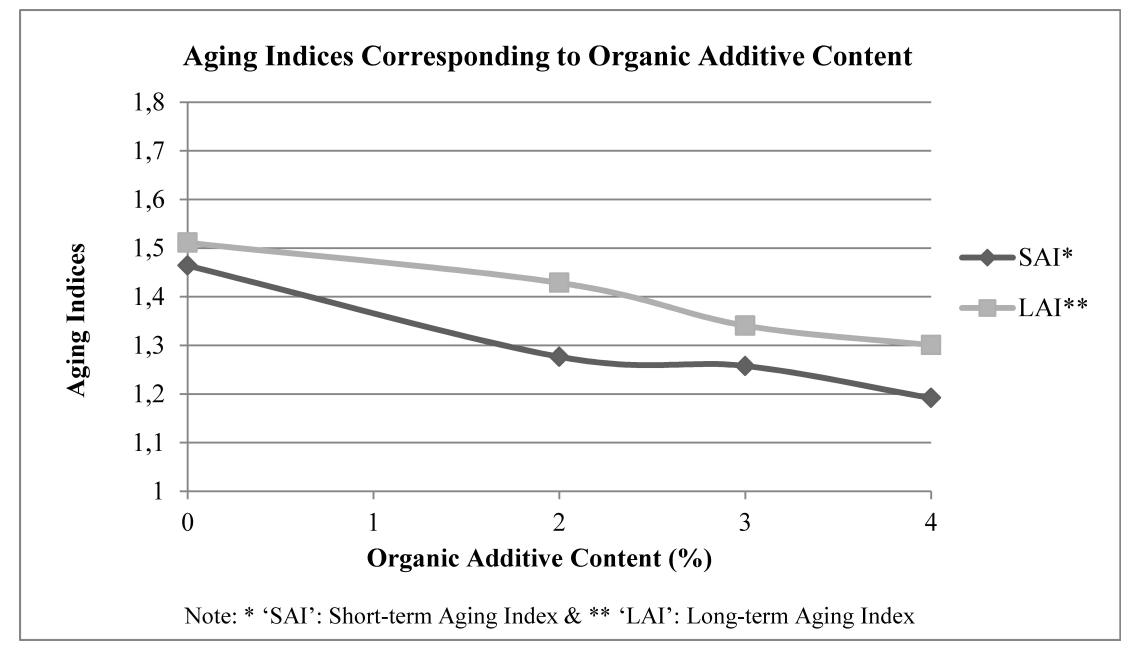

Fig. 7. Aging Indices corresponding to organic additive contents

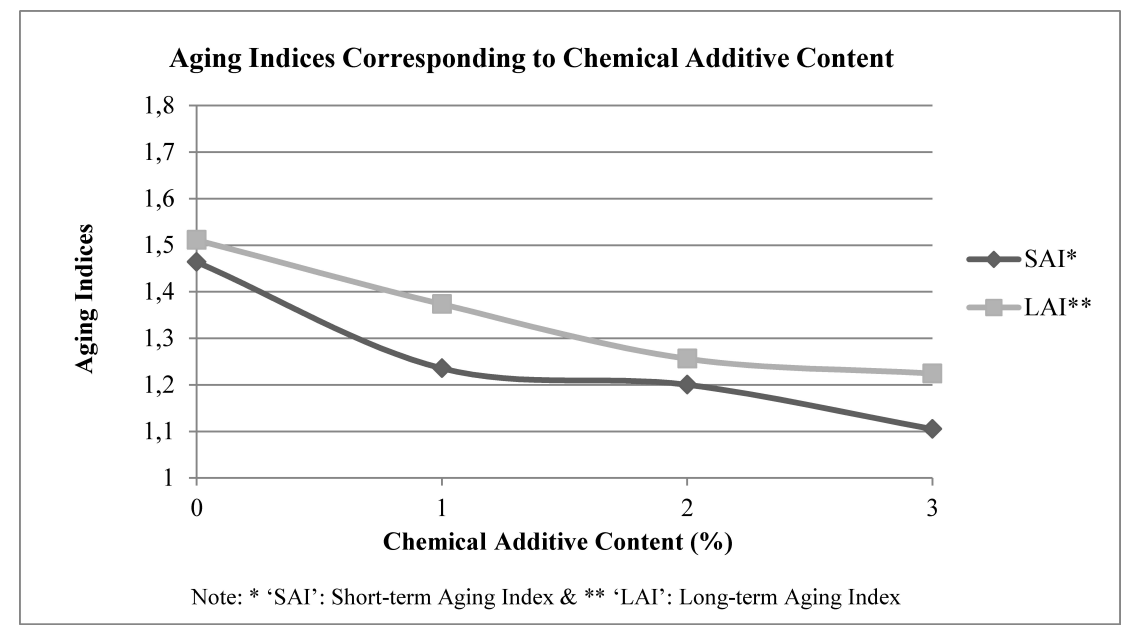

Fig. 8. Aging Indices corresponding to chemical additive contents

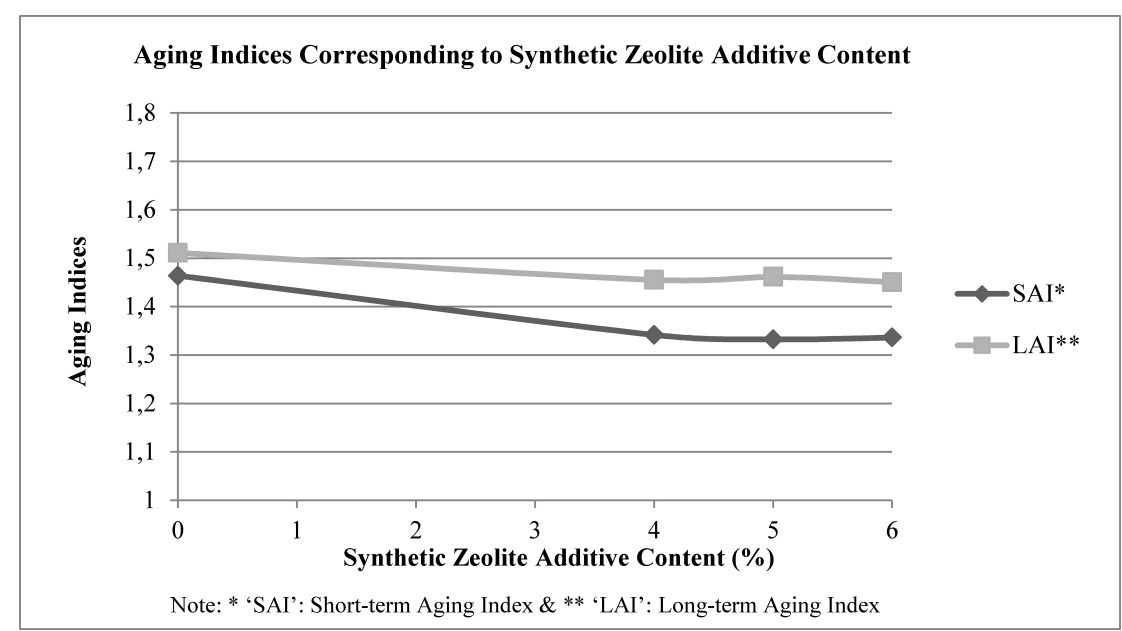

Fig. 9. Aging Indices corresponding to synthetic zeolite additive contents 


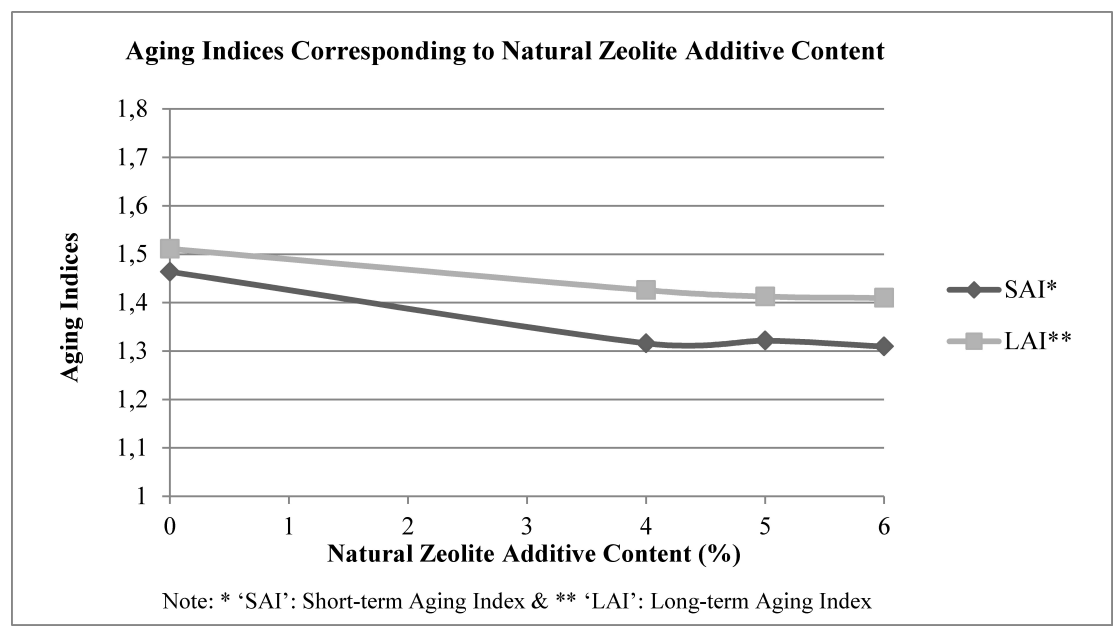

Fig. 10. Aging Indices corresponding to natural zeolite additive contents

against aging among all additives tested within the scope of this research. Organic additive could exhibit itself as an acceptable interceptor against aging. For both organic and chemical additives, it is evident that the hardening rate is reduced when the additive content increases. The reduction slope declines in step by step increasing in additive content.

\section{Conclusions and recommendations}

Like every structure in civil engineering, an asphalt pavement has a service life. The more the service life of an asphalt pavement, the more economic that asphalt pavement is. In terms of engineering economy, simply considering the initial cost of a structure is not the only important task that an engineer should perform, but it is important to consider the service life of that particular structure. Although WMA technologies have a lot of economic benefits in comparison to HMA pavements in terms of energy efficiency and environmental susceptibility, it is essential to consider the service life of these types of pavements. As aforementioned, this study was allocated to evaluate the aging effects of WMA additives on bituminous mixtures.

The conventional bitumen tests indicated the increase in softening point and reduction in temperature susceptibility (as determined by the penetration index-PI) of the bitumen samples involving WMA additives. Lower values of PI indicate higher temperature susceptibility. Asphalt mixtures containing bitumen with higher PI are more resistant to low temperature cracking as well as permanent deformation. Besides the addition of WMA additives decrease the retained penetration value of the bitumen samples which simulates the aging of the bitumen during mixing of the aggregate, transportation to the landsite and compaction in the field. This indicated that the addition of WMA additives is less affected during short term aging.

Within the scope of the study, the term aging indice is used to represent the durability of the bituminous mixtures involving different types of WMA additives. Taking into consideration the defined indices, WMA exhibited better performance than conventional HMA in the overall evaluation. Besides, nonfoaming additives demonstrated better aging indices in compari- son to foaming additives. Among the non-foaming additives the chemical WMA additive exhibited better performance than organic additive meanwhile natural zeolite performed better than synthetic zeolite additive among foaming additives.

As a conclusion, WMA technologies can be categorized as acceptable alternatives for conventional HMA pavements especially taking the durability factors into account. Also, natural zeolite can be used as an alternative WMA additive to synthetic zeolite. Utilization of WMA additives in lower temperatures is the dominating advantage of WMA technologies from the aging point of view.

Since the WMA technologies are relatively new, the future research for these technologies include a wide area of expertise. Within the scope of this study, it was attempted to comparatively evaluate the aging phenomenon of bituminous mixtures involving a natural WMA additive beside three kinds of commercial warm mix additives. Further investigations should be carried out using different kind of WMA additives. And also new researches are recommended to conduct on microscope images of additives with bitumen to study microstructural characterization of aged and unaged bitumen samples.

\section{Acknowledgements}

This research was sponsored by the Scientific and Technical Research Council of Turkey (TUBITAK) under the project number 110M567 for which the authors are greatly indebted. Besides, this study has been carried out with the valuable contribution of Dokuz Eylul University, The Graduate School of Natural and Applied Sciences.

\section{References}

1 Carnesale A, America's Climate Choices: Chameides, W, NRC/NAS USA Committee on America's Climate Choices, 2011.

2 National Research Council, Advancing the Science of Climate Change, The National Academies Press; Washington, DC, 2010, ISBN 978-0-30914588-6.

3 Bocz $\mathbf{P}$, The effect of stiffness and duration parameters to the service life of the pavement structure, Periodica Polytechnica Civil Engineering, 53(1), (2009), 35-41, DOI 10.3311/pp.ci.2009-1.05 
4 D'Angelo J, Harm E, Bartosze J, Baumgardner G, Corrigan M, Cowsert J, Harman T, Jamshidi M, Jones W, Newcomb D, Prowell B, Sines R, Yeaton B, Warm-Mix Asphalt: European practice, American trade initiatives, 2008.

5 Bell C, Summary Report on Aging Of Asphalt-Aggregate Systems, Transportation Research Board, 1989.

6 Wright J, Campbell P, Determination of oxidation rates of air-blown asphalts by infra-red spectroscopy, Journal of Applied Chemistry, 12(6), (1962), 256-266, DOI 10.1002/jctb.5010120604

7 Chipperfied E, Duthie J, Girdler R, Asphalt Characteristics in Relation to Road Performance, Association of Asphalt Paving Technologists, 1970.

8 Petersen $\mathbf{J}$, Chemical composition of asphalt as related to asphalt durability: state of the art, Transportation Research Record, 999, (1984), 13-30.

9 Bell C, Wieder A, Fellin M, Laboratory Aging of Asphalt-Aggregate Mixtures: Field Validation: field validation, Oregon State University; Corvallis, 1994.

10 Tóth C, Ureczky J, Determination of master curves for asphalt mixtures by means of IT-CY tests, Periodica Polytechnica Civil Engineering, 54(2), (2010), 137-142, DOI 10.3311/pp.ci.2010-2.09

11 Xiaohu L, Isaccson U, Artificial aging of polymer modified bitumens, Journal of Applied Polymer Science, 76(12), (2000), 1811-1824, DOI 10.1002/(SICI)1097-4628(20000620)76:12<1811::AID-APP12>3.0.CO;21

12 Rubio M, Martinez G, Baena L, Moreno F, Warm Mix Asphalt: an overview, Journal of Cleaner Production, 24, (2012), 76-84, DOI 10.1016/j.jclepro.2011.11.053

13 Zettler R, Road manager: warm mix stands up to its trials, Better Roads, 76(2), (2006), 16-21.

14 Capitão SD, Picado-Santos LG, Martinho F, Pavement engineering materials: Review on the use of warm-mix asphalt, Construction and Building Materials, 36, (2012), 1016-1024, DOI 10.1016/j.conbuildmat.2012.06.038

15 Chowdhury A, Button JW, A review of warm mix asphalt, Texas Transportation Institute, the Texas A\&M University System, 2008.

16 Lai JS, Tsai JY, Evaluating constructability and properties of warm mix asphalt, Georgia Institute of Technology (Atlanta), 2010.

17 Xiao F, Amirkhanian SN, Effects of liquid antistrip additives on rheology and moisture susceptibility of water bearing warm mixtures, Construction and Building Materials, 24(9), (2010), 1649-1655, DOI 10.1016/j.conbuildmat.2010.02.027

18 Zaumanis M, Haritonovs $\mathbf{V}$, Research on properties of warm mix asphalt, The Scientific Journal of Riga Technical University, 11, (2010), 77-84.

19 Jones D, Tsai B, Signore J, Warm-mix asphalt study: laboratory test results for AkzoNobel RedisetTM WMX, University of California Pavement Research Center (UCPRC), 2010.

20 ASTM D5-06, Standard test method for penetration of bituminous materials, American Society for Testing and Materials; West Conshohocken, PA, 2006.

21 ASTM D36-95, Test method for softening point of bitumen (ring-and-ball apparatus), American Society for Testing and Materials; West Conshohocken, PA, 2000.

22 ASTM D1754-97, Standard test method for effects of heat and air on asphaltic materials (thin-film oven test), American Society for Testing and Materials; West Conshohocken, PA, 2002.

23 ASTM D2872-12, Standard test method for effect of heat and air on a moving film of asphalt (rolling thin-film oven test), American Society for Testing and Materials; West Conshohocken, PA, 2012.

24 EN 13399, Bitumen and bituminous binders-determination of storage stability of modified bitumen, European Committee for Standardization; Avenue Marnix 17, B-1000 Brussels, 2010.

25 ASTM D4402-12, Standard test method for viscosity determination of asphalt at elevated temperatures using a rotational viscometer, American Society for Testing and Materials; West Conshohocken, PA, 2012.
26 ASTM D2493-09, Standard viscosity-temperature chart for asphalts, American Society for Testing and Materials; West Conshohocken, PA, 2009.

27 AASHTO R 30, Standard practice for mixture conditioning of hot mix asphalt (HMA), American Association of State Highway and Transportation Officials (AASHTO); Washington, 2002.

28 ASTM D6931-12, Standard test method for indirect tensile (IDT) strength of bituminous mixtures, American Society for Testing and Materials; West Conshohocken, PA, 2012.

29 Anderson RM, Christensen DW, Bonaquist R, Estimating the rutting potential of asphalt mixtures using Superpave gyratory compaction properties and indirect tensile strength (with discussion), Journal of the Association of Asphalt Paving Technologists, 72, (2003), 1-26.

30 Sengoz B, The effect of asphalt film thickness on the aging and moisture susceptibility of hot mix asphalt, $\mathrm{PhD}$ thesis, Istanbul Technical University; Istanbul, Turkey, 2003.

31 Liang RY, Lee SJ, Bonaquist R, Short-term and long-term aging behavior of rubber modified asphalt paving mixture, Transportation Research Record: Journal of the Transportation Research Board, 1530, (1996), 11-17, DOI $10.3141 / 1530-02$

32 Sengoz B, Topal A, Effect of SBS polymer modified bitumen on the ageing properties of asphalt, The 4th Eurasphalt and Eurobitume Congress, In: Proceedings of the Eurasphalt \& Eurobitume Congress in Copenhagen in 2008; Copenhagen, 2008.

33 Hurley GC, Prowell BD, Signore J, Evaluation of sasobit $\AA$ for use in warm mix asphalt, National Center for Asphalt Technology, 2005.

34 Sengoz B, Isikyakar G, Short-term and long-term aging behavior of rubber modified asphalt paving mixture, Journal of Hazardous Materials, 150(2), (2008), 424-432, DOI 10.1016/j.jhazmat.2007.04.122

35 Prowell BD, Hurley GC, Warm-mix asphalt: Best practices, National Asphalt Pavement Association, 2007. 